the electrolysis of this double salt in the fused state, and from the oxide, by reduction with carbon in the electric furnace. All three processes give good yields, the last-mentioned being the best, if care be taken not to unduly prolong the heating in contact with carbon, and to exclude air.

Metallic uranium, when pure, is perfectly white, and is not magnetic if free from iron. It is not hard enough to scratch glass, takes a good polish, and can be filed with ease; in the electric forge it is much more volatile than iron.

M. Henri Becquerel, in the same number of the Comptes rendus, gives an account of a remarkable property of this metal, which appears to be unique, that of emitting in visible phosphorescent rays capable of producing photographic effects after travessing opaque bodies such as cardboard, aluminium, copper, and platinum, and also able to discharge a gold leaf electroscope. The effects produced are precisely similar to those previously obtained from uranium salts, such as potassium uranyl sulphate, except that they are nearly four times as intense. The chenical behaviour of uranium depends to a certain extent upon its state of division. The metal obtained by electrolysis, which is finely divided, takes fire in fluorine, is attacked by chlorine at $180^{\circ}$, by bromine at $210^{\circ}$, and by iodine at $260^{\circ}$, the reactions in all cases being complete. The powdered metal is completely burned in pure oxygen at $\mathrm{I}^{\circ} \mathrm{O}^{\circ}$, and decomposes water, siowly at the ordinary temperature but more quickly at $100^{\circ}$. Uranium must be added to the rapidly increasing group of metals which combine directly with nitrogen at high temperatures. Fragments of the metal heated to about $1000^{\circ}$ in a current of nitrogen become covered with a yellow layer of nitride, and hence in the preparation of the metal it is necessary to work in such a manner as to completely exclude air.

\section{SCIENCE IN THE MAGAZINES}

TIIE celebration of the Kelvin jubilee at Glasgow on June ${ }^{5}$ 17 , makes the appearance of an article on the renowned in vestigator, in the June number of Good Words, very opportune. The author is the editor, Dr. Donald Macleod, once a student of Lord Kelvin's, and his description of the master is a most appreciative one. Illustrations of Glasgow University, Lord Kelvin's class-room, laboratory, and study, and of Lord and Lady Kelvin, give additional interest to the article.

An excellent illustrated article on "The Rise of the Royal Society," is contributed to the Leisure Hour by Mr. Herbert Rix, the late Assistant Secretary of the Society. Other articles of scientific interest in the same magazine are "Notes on the Zoo," by Mr. W. J. Gordon, with illustrations from photographs by Mr. Gambier Bolton; "The New South Africa," by Mr. Basil Worsfold; and "Modern Hygiene in Practice," by Dr. A. T. Schofield.

Sience Gossip contains the first of a series of articles upon the scientific worthies at the National Portrait Gallery, illustrated with sketches of the pictures by Miss J. Hensman. We understand from the article that there are about thirty portraits of scientific men out of upwards of a thousand pictures in the Gailery.

An article on Africa since I888, with special reference to Sonth Africa and Abyssinia, by the Hon. Gardiner G. Hubbard, and accompanied by a striking portrait of the author, appears in the National Geographic Magazine (May). Another paper on Africa, "Impressions of South Africa," is contributed to the Century Magazine by Mr. James Bryce, M.P. In the Contemporary, there is an article by Dr. George Harley, F.R.S., on "Champagne," having medical as well as gustatory points of interest. Good Words has an article on "Aluminium," by Prof. Jamieson, and on "Flowers of the Forest," by Mr. Edward Step. Mr. W. H. Hudson has an article on "Ravens in Somersetshire" in Longman's Mayazine. Among the popular articles in Chambers's Journal is one on "Photography in Colours," descriptive of Mr. Ives' process, and another on the Harvey process for hardening steel. Sir Robert Ball describes the planet Saturn in the Strand Magasine. Student of animal life may be interested in the second paper on "The Evolution of the Trotting Horse," contributed by Mr. H. Busbey to Siribner.

In addition to the periodicals mentioned, we have received the Humanitarian, Fortnishtly, and the Sunday Magazine, but no articles in them call for notice here.

No. I 388 , voL. 54]

\section{UNIVERSITY AND EDUCATIONAL INTELLIGENCE.}

Mr. H. J. Heinty has given Io,000 dols. to the Kansas City University, the corner-stone of which has just been laid.

THE Technical Instruction Committee of the Middlesex County Council have decided to offer a scholarship, worth $£ 50$ per year for two years, tenable at the City and Guilds of London Institute. This scholarship is to be competed for by boys to whom scholarships at secondary schools were awarded in 1893 . It is to include school fees, railway fares, and maintenance.

THE following are among recent announcements:-Dr. Otto Fischer to be Extraordinary Professor of Mathematics in Leipzig University; Prof. L. M. Underwood to be called to the chair of Botany in Columbia University; Dr. George $A$ Dorsey to be Curator in the Department of Anthropology in the Field Columbian Museum at Chicago; Dr. Franz Boas to be Lecturer on Physical Anthropology in Columbia Unirersity; Prof. Harold B. Smith to be Professor of Electrical Engineering in the Worcester Polytechnic Institute.

For news of the following gifts to education and research in America, we are indebted to Sicence:-Mr. Thomas McKean has offered to give 100,000 dols. to the University of Pennsylvania upon condition that $\mathrm{I}, 000,000$ dols. be collected. Mr. McKean, who is a trustee and an alumnus of the University, gave 50,000 dols. about a year ago.---Mr. Charles M. Dalton has given the Massachusetts Institute of Technology 5000 dols. for a scholarship in chemistry for graduate students. Preference will be given to those undertaking chemical research applicable to textile fabrics.-Real estate and securities valued at 2 15,000 dols. have been presented to the North-western University by William Deering, of Evanston, who had previously given the University about 200,000 dols.

WE have to record another attempt to divert part of the funds available under the Local Taxation (Customs and Excise) Act. I890, to the General County Fund. This time it is the Isle of Ely County Council. At their meeting held at March, on May 20 , it was proposed " that $£ 1000$ of the Imperial grant be allocated to the General County Fund, instead of the $f \mathrm{I} 50$ recommended by the Committee." The proposal was eventually rejected, it is true, but only by a majority of two in a meeting of forty. The argument which was used in the North Riding County Council a short time ago, and to which we called attention, was again repeated-that it was never the intention of Parliament for the whole of these funds to be devoted to the purposes of technical education. No stronger reason than such occurrences as these could be found for the necessity of the provision in the Elucation Bill that these funds must be devoted to educational purposes.

WE are glad to learn from Science that an effort is now under way in connection with the National Educational Association to bring about greater interest in the teaching of science than has hitherto been shown by American botanists, zoologists, chemists, physicists, \&c. The new Department of Natural Science In struction is intended to bring together the teachers of the natural sciences who are interested in science as a means of culture, and to stimulate thought and discussion as to how this end may best be obtained. What róle should botany, zoology, chemistry, physics, \&c., play in the mental development of man? In what way may the study of plants, animals, chemical compounds and physical forces be made an efficient factor in a man's mental training? When and how shall such study be made a part of a man's training? These are some of the questions which will be discussed in the Department of Natural Science Instruction in the Buffalo meeting of the National Educational Association, on Thursday and Friday afternoons (July 9 and Io).

THE Technical Instruction Committees of the Oxfordshire County Council have decided to devote $£ 560$ to scholarships during the next year. Of this amount $£ 294$ will be absorbed on account of the scholars already elected. The balance is to be devoted to further developing the scholarship scheme. Amongst other arrangements, we notice that it is proposed to elect three sons of tenant farmers to County Council scholarships of an annual value of $f \mathrm{I}_{5}$. The candidates must have been under fourteen years of age on December 3I, I895, and must have lived in the county for two years previously. The scholarships will be held at Burford Grammar School for the first two years. Sums of $£ 366$ and $£ 314$ have been respectively allotted for capitation 